\title{
Assessment of wind characteristics and wind turbine characteristics in Taiwan
}

\author{
Tsang-Jung Chang ${ }^{\mathrm{a}, *}$, Yu-Ting Wu ${ }^{\mathrm{a}}$, Hua-Yi Hsu ${ }^{\mathrm{a}}$, \\ Chia-Ren Chu ${ }^{b}$, Chun-Min Liao ${ }^{a}$ \\ ${ }^{a}$ Department of Bioenvironmental Systems Engineering, National Taiwan University, Taipei, 10617 \\ Taiwan \\ b Department of Civil Engineering, National Central University, Taoyuan, 32054 Taiwan
}

Received 23 July 2002; accepted 8 September 2002

\begin{abstract}
Wind characteristics and wind turbine characteristics in Taiwan have been thoughtfully analyzed based on a long-term measured data source (1961-1999) of hourly mean wind speed at 25 meteorological stations across Taiwan. A two-stage procedure for estimating wind resource is proposed. The yearly wind speed distribution and wind power density for the entire Taiwan is firstly evaluated to provide annually spatial mean information of wind energy potential. A mathematical formulation using a two-parameter Weibull wind speed distribution is further established to estimate the wind energy generated by an ideal turbine and the monthly actual wind energy generated by a wind turbine operated at cubic relation of power between cut-in and rated wind speed and constant power between rated and cut-out wind speed. Three types of wind turbine characteristics (the availability factor, the capacity factor and the wind turbine efficiency) are emphasized. The monthly wind characteristics and monthly wind turbine characteristics for four meteorological stations with high winds are investigated and compared with each other as well. The results show the general availability of wind energy potential across Taiwan.
\end{abstract}

(C) 2002 Elsevier Science Ltd. All rights reserved.

Keywords: Wind energy; Wind characteristics; Wind turbine characteristics; Weibull wind speed distribution; Taiwan

* Corresponding author. Fax: 886-2-23635854.

E-mail address: tjchang@ccms.ntu.edu.tw (T.-J. Chang). 


\section{Introduction}

Taiwan, a rapidly industrializing society with population density as high as 602 people $/ \mathrm{km}^{2}$ (22 million people within an island of $36,000 \mathrm{~km}^{2}$ ), has faced a number of energy utilization challenges at the beginning of the 21 st century. Firstly, $89 \%$ of total energy supply in 2000 came from imported fossil fuels (petroleum $51 \%$, coal $31 \%$, and natural gas 7\%) [1]. Availability of imported energy supplies and fluctuations in international energy prices strongly influences island-wide economic development. The newly elected government has decided not to construct any new nuclear power plants in the future, and the currently operating nuclear power plants (9\% of the total energy supply) will be halted gradually. It is expected that the increasing use of fossil fuels would result in rapidly increasing $\mathrm{CO}_{2}$ emissions, which apparently violates the implementation of the Kyoto Protocol. Secondly, the concentrated power supply system is connected by two $345 \mathrm{KV}$ transmission lines and hence reduces the independence and flexibility of regional power supplies during natural disasters such as earthquakes and typhoons. The island-wide power supply system shut down twice in 1999 due to a landslide-induced transmission tower failure in central Taiwan in July and a severe earthquake occurring in September. To face the aforementioned energy utilization challenges, the government has begun to react, including planning the utilization of renewable energy sources.

The global wind energy industry has been setting a record for newly installed generating capacity since the late 1990s. Technological progress has also dramatically reduced the price of wind power in favorable locations in such a way that the rate of growth appeared likely to maintain wind's position as one of the world's fastest growing energy sources [2]. Besides, the wind climate in Taiwan, including the Asia monsoon and tropical cyclones during the summer season and the northeast trade winds during the winter season, induces high winds in many places. As a result, among various renewable energy sources in Taiwan, wind energy could be in the short term one of the most promising renewable energy sources. It could provide a much greater proportion of energy production in places with good wind.

Academic attempts regarding the evaluation of wind energy potential for different regions by using various probability distribution functions have been carried out by some researchers. Most of the researches have indicated that the Weibull wind speed distribution is accurate for wind energy estimation [3]. Jamil et al. [4] developed an evaluation method to estimate wind energy density and other wind characteristics in Iran based on the two-parameter Weibull wind speed distribution. Rosen et al. [5] used two kinds of the Weibull distributions to analyze wind potential energy of two windy sites located in the coastal region of Red Sea. Eritrea. Li [6] and Lu et al. [7] conducted mathematical investigations using the two-parameter Weibull wind speed distribution to examine wind power potential and wind turbine characteristics in Hong Kong. Recently, Mathew et al. [8] presented an analytical approach to study the wind energy density, energy available in the wind spectra, and the energy received by turbine by using the Rayleigh wind speed distribution. Jangamshetti and Rau [9] and Balouktsis et al. [10] addressed a statistical model and nomogram 
method to investigate wind turbine characteristics for various wind turbine generators by using the same sets of wind data at Kappadgudda wind power station, India.

The above studies either investigated wind characteristics (wind speed and wind energy density) only, or focused on part of wind turbine characteristics of a given wind turbine generator such as the capacity factor. For example, for a very large rotor together with a very small generator, a wind turbine would run at full capacity and thus achieve a very high capacity factor. But it could produce very little electricity, resulting in low wind turbine efficiency. In such a situation, considering only the capacity factor cannot provide overall information on wind turbine characteristics. To understand in depth wind turbine characteristics of a given generator for different locations, three types of wind turbine characteristics (the availability factor, the capacity factor and the wind turbine efficiency of a chosen wind turbine) are addressed and investigated. A two-stage procedure for estimating wind resources in Taiwan is firstly evaluated. The monthly wind speed distributions, wind power densities, and aforementioned wind turbine characteristics are next studied and used to map out the general availability of wind energy potential across Taiwan.

\section{Mathematical formulation}

There are several continuous mathematical functions, or called the probability density functions, that can be used to model the wind speed frequency curve by fitting time-series measured data. In wind power studies, the Weibull and Rayleigh probability density functions are commonly used and widely adopted [3]. Herein the Weibull distribution is used since the Rayleigh distribution is only a subset of it.

\subsection{Weibull distribution of wind speed}

The Weibull probability density function is a special case of a generalized twoparameter Gamma distribution. Weibull distribution can be characterized by its probability density function $f(V)$ and cumulative distribution function $F(V)$ as follows:

$$
f(V)=\frac{k}{c}\left(\frac{V}{c}\right)^{k-1} e^{-(V / c)^{k}}
$$

and

$$
F(V)=1-e^{-(V / c)^{k}}
$$

where $c$ is the scale parameter, $k$ is the shape parameter, and $V$ is wind speed. The scale and shape parameter can be estimated by using the maximum likelihood method [11] as suggested in the following iterative Eqs. [11]

$$
k=\left(\frac{\sum_{i=1}^{n} V_{i}^{k} \ln \left(V_{i}\right)}{\sum_{i=1}^{n} V_{i}^{k}}-\frac{\sum_{i=1}^{n} \ln \left(V_{i}\right)}{n}\right)^{-1}
$$




$$
c=\left(\frac{1}{n} \sum_{i=1}^{n} V_{i}^{k}\right)^{1 / k}
$$

where $V_{\mathrm{i}}$ is the wind speed in time stage $i$ and $n$ is the number of non zero wind speed data points.

As the scale and shape parameter have been calculated, two meaningful wind speeds for wind energy estimation, the most probable wind speed and the wind speed carrying maximum energy, can be easily obtained. The most probable wind speed denotes the most frequent wind speed for a given wind probability distribution and is expressed by

$$
V_{\mathrm{MP}}=c\left(\frac{k-1}{k}\right)^{1 / \mathrm{k}} \text {. }
$$

The wind speed carrying maximum energy represents the wind speed which carries the maximum amount of wind energy, and is expressed as follows [4]:

$$
V_{\text {MaxE }}=c\left(\frac{k+2}{k}\right)^{1 / k}
$$

\subsection{Wind power density}

It is well known that the power of the wind that flows at speed $V$ through a blade sweep area $A$ increases as the cubic of its velocity and is given by

$$
P(V)=\frac{1}{2} \rho A V^{3}
$$

where $\rho$ is fluid density. Wind power density of a site based on a Weibull probability density function can be expressed as follows $[3,4]$ :

$$
\frac{P}{A}=\int_{0}^{\infty} P(V) f(V) d V=\frac{1}{2} \rho c^{3} \Gamma\left(\frac{k+3}{k}\right)
$$

where $\Gamma$ denotes the Gamma function. Once wind power density of a site is given, the wind energy density for a desired duration (a month or a year) can be expressed as

$$
\frac{E}{A}=\frac{1}{2} \rho c^{3} \Gamma\left(\frac{k+3}{k}\right) T
$$

where $T$ the time period (or duration). For example, $T$ is $720 \mathrm{hr}$ for monthly duration.

\subsection{Wind energy generated by an ideal wind turbine}

A wind turbine is basically designed to convert wind energy to electrical energy. For an ideal wind turbine, the wind energy available in the wind can be completely 
extracted so that the turbine rotor starts to function at cut-in speed $V_{\mathrm{I}}$ and power generated increases as wind speed increases until it reaches the rated wind speed $V_{\mathrm{R}}$. At wind speeds between the rated wind speed and cut-off wind speed $V_{\mathrm{O}}$, a constant rated power is generated corresponding to the rated wind speed by $P_{R}=$ $1 / 2 \rho A V_{R}^{3}$. At wind velocities exceeding cut-off wind speed, the turbine is completely shut down. As a result, the wind energy generated by an ideal wind turbine operated at an increasing relation of power between cut-in and rated wind speed and a constant rate power $P_{\mathrm{R}}$ between rated and cut-out wind speed can be given by

$$
E_{T W}=T \int_{0}^{\infty} P(V) f(V) d V=T\left(\int_{V_{I}}^{V_{R}} P(V) f(V) d V+\int_{V_{R}}^{V_{O}} P_{R} f(V) d V\right)
$$

Substituting $P(V)=1 / 2 \rho A V^{3}$ and a constant rated power generated by an ideal wind turbine $P_{R}=1 / 2 \rho A V_{R}^{3}$ into Eq. (10) yields

$$
E_{T W}=\frac{\rho}{2} T A\left(\int_{V_{I}}^{V_{R}} V^{3} \frac{k}{c}\left(\frac{V}{c}\right)^{k-1} e^{-(V / c)^{k}} d V+V_{R}^{3} \int_{V_{R}}^{V_{O}} \frac{k}{c}\left(\frac{V}{c}\right)^{k-1} e^{-(V / c)^{k}} d V\right)
$$

The integrals in Eq. (11) cannot be analytically solved, but they can be easily calculated by any typical numerical integration techniques such as Simpson's rule or Gauss quadrature. Herein the six-point Gauss-Legendre quadrature is used.

\subsection{Actual wind energy output from a wind turbine}

The power in the wind is converted into the mechanical-rotational energy of a wind turbine rotor, which would reduce the speed of the air mass. The wind energy available in the wind cannot be extracted completely by any real wind turbine, as the air mass would be stopped completely in the intercepting rotor area. For wind turbine machines that operate at constant power $P_{R}$ with maximum efficiency between rated and cut-out speed and at increasing power between cut-in and rated speed, the actual wind power output from the wind turbine $P_{T}$ is determined by the turbine performance curve, which is well described by the following expression.

$$
P_{T}(V)= \begin{cases}0 & , V<V_{I} \\ \left(a_{1} V^{3}+a_{2} V^{2}+a_{3} V+a_{4}\right) & P_{R}, V_{I} \leq V<V_{R} \\ P_{R} & , V_{R} \leq V<V_{O} \\ 0 & , V \geq V_{O}\end{cases}
$$

where $a_{1}, a_{2}, a_{3}$, and $a_{4}$ are regression constants of the turbine performance curve. It should be noted that using a cubic function in Eq. (12) is only for regression purpose. It is desirable to use other polynomial functions to fit the turbine perform- 
ance curve. Taking the Vestas V47-660 KW turbine [12] as example, Fig. 1 depicts the performance curve of this turbine, in which the rate power is $P_{R}=660 \mathrm{KW}$. This turbine has a rotor diameter of $47 \mathrm{~m}$ (the blade sweep area $A=1,735 \mathrm{~m}^{2}$ ) and a hub height of $45 \mathrm{~m}$. The cut-in, rated, and cut-off speed are $4 \mathrm{~m} / \mathrm{s}, 15 \mathrm{~m} / \mathrm{s}$, and $25 \mathrm{~m} / \mathrm{s}$, respectively. The regressed values of $a_{1}, a_{2}, a_{3}$, and $a_{4}$ in Eq. (12) are $0.00169,0.04446,-0.24764$, and 0.39209 , respectively.

Combining Eqs. (1), (7) and (12) yields the actual wind energy output from a wind turbine in the following, which is the output electrical power at each wind speed $P_{T}(V)$ multiplied by the probability of the wind speed experienced $f(V)$ and integrated over all possible wind speeds.

$$
\begin{array}{r}
E_{T A}=T \int_{V_{I}}^{V_{O}} P_{T}(V) f(V) d V=T P_{R} \int_{V_{I}}^{V_{R}}\left(a_{1} V^{3}+a_{2} V^{2}+a_{3} V\right. \\
\left.+a_{4}\right) \frac{k}{c}\left(\frac{V}{c}\right)^{k-1} e^{-(V / c)^{k}} d V+T P_{R} \int_{V_{R}}^{V_{O}} \frac{k}{c}\left(\frac{V}{c}\right)^{k-1} e^{-(V / c)^{k}} d V .
\end{array}
$$

The integrals in Eq. (13) are also calculated by the six-point Gauss-Legendre quadrature. The typical wind-speed probability densities of Taiwan in January and August are also plotted in Fig. 1. The wind energy integration in Eq. (13) can be clearly seen in Fig. 1, which reveals that the actual wind energy produced in August is more than in January.

\subsection{Wind turbine efficiency, capacity factor, and availability factor of a wind} turbine

Since the wind energy available in the wind cannot be completely extracted by any wind turbine, the wind turbine efficiency $\eta$, defined as the ratio of the actual

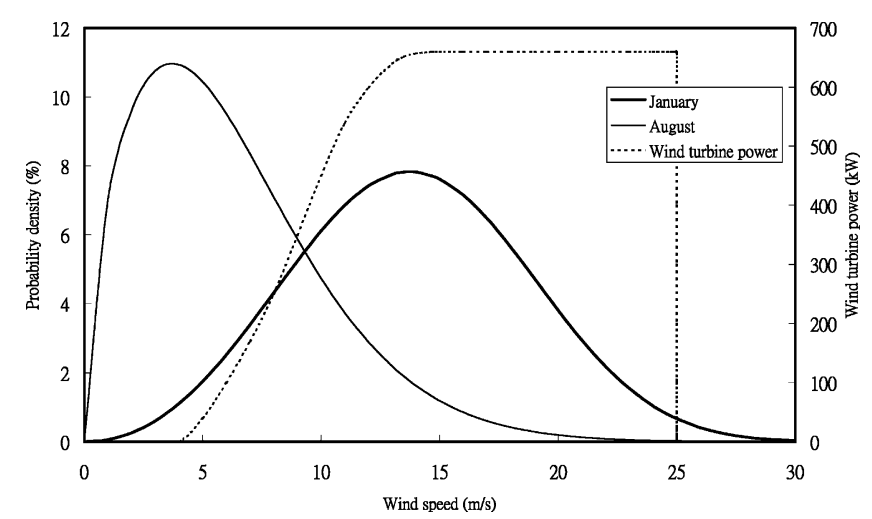

Fig. 1. The performance curve of the Vestas V47-660 KW turbine and typical wind-speed probability densities in January and August in Taiwan. 
wind energy output from a wind turbine to the wind energy generated by an ideal wind turbine, is meaningful for evaluating turbine performance and can be expressed as the ratio of Eq. (13) to Eq. (11).

$$
\eta=\frac{E_{T A}}{E_{T W}} .
$$

It can be seen from Eqs. (11), (13) and (14) that the wind turbine efficiency is not only a function of wind turbine performance, but also a function of wind speed distribution. The wind turbine efficiency enables us to figure out the relationship between energy available in the wind and how much energy a turbine can transfer. It is important to note that the theoretical optimum for utilizing the power in the wind by reducing its speed was first discovered by Betz in 1926, as shown in many wind energy textbooks [2,3]. According to Betz, under the assumption that the turbine swirl and transmission losses were neglected, the theoretically maximum power that can be extracted from the wind is $59 \%$ of the wind power available in the wind. Therefore, for any wind turbine, the wind turbine efficiency $\eta$ should not exceed 0.59 .

On the other side, the capacity factor is also an important index in measuring the productivity of a wind turbine. It compares the actual power production of a turbine over a given duration with the amount of power of the turbine operated at maximum output $100 \%$ of the same amount of duration. A wind turbine operating with the full capacity for a duration $T$ can produce so called the rated wind energy as follows:

$$
E_{T R}=T P_{R}
$$

Dividing the actual energy production of a wind turbine by the rated wind energy yields the capacity factor as

$$
\begin{aligned}
C_{F}= & \frac{E_{T A}}{E_{T R}}=\int_{V_{I}}^{V_{R}}\left(a_{1} V^{3}+a_{2} V^{2}+a_{3} V+a_{4}\right) \frac{k}{c}\left(\frac{V}{c}\right)^{k-1} e^{-(V / c)^{k}} d V \\
& +\int_{V_{R}}^{V_{O}} \frac{k}{c}\left(\frac{V}{c}\right)^{k-1} e^{-(V / c)^{k}} d V
\end{aligned}
$$

The availability factor is defined as a measurement of the operation percentage of a wind turbine. It refers to the percentage of time that a wind turbine is operating, which depends on wind turbine characteristics and wind energy potential. For a wind turbine having the cut-in speed $V_{\mathrm{I}}$ and cut-off speed $V_{\mathrm{O}}$, the availability factor $A_{F}$ is the probability of $P\left(V_{I} \leq V<V_{O}\right)$, which can be calculated using the following equation.

$$
A_{F}=P\left(V_{I} \leq V<V_{O}\right)=\int_{V_{I}}^{V_{O}} \frac{k}{c}\left(\frac{V}{c}\right)^{k-1} e^{-(V / c)^{k}} d V
$$


In general, the availability factor increases as the decrease of the cut-in wind speed of a wind turbine and the increase of the cut-off wind speed and mean wind speed. Most modern wind turbines have high values of the availability factor. However, much of the time it can be utilizing part of the power in the wind and it will be generating at less than full capacity, which is determined by the other two factors, i.e., the wind turbine efficiency and the capacity factor.

For example, with a very large rotor and a very small generator, a wind turbine would run at full capacity in such a way that its capacity factor remains high. But it could produce very little electricity, resulting in low wind turbine efficiency. On the contrary, for the same rotor together with a very large generator, the capacity factor will be lower as a result but the wind turbine efficiency could be higher. Consequently, to completely describe wind turbine characteristics, the availability factor, the capacity factor, and the wind turbine efficiency of a specific wind turbine should be considered together. Table 1 gives the wind energy characteristics for twoparameter Weibull distribution and all of the wind turbine characteristics used in the present study.

\section{Case study of wind characteristics and wind turbine characteristics}

Taiwan is located in the East Asia subtropical zone with an area of $36,000 \mathrm{~km}^{2}$. The Central Mountains are across Taiwan from north to south with average elevation of $1500 \mathrm{~m}$. The wind regime of Taiwan during a year is largely characterized by the same mechanisms, including the Asia monsoon and tropical cyclones during summer and fall seasons, the northeast trade winds during winter and spring, and local convergence of the wind environment due to the Central Mountains. The Asia monsoon climate is predominant with southern or southwestern winds from May to October, whereas strong trade winds blow with accelerated speeds and wind direction suddenly changing to northeastern during winter and spring season (from November to April). As a combined effect of the aforementioned mechanisms, the patterns of the yearly and monthly mean wind speed over Taiwan are highly variable, both spatially and temporally. In addition, the tropical cyclone season comes during the period May to November, in which typhoons and tropical cyclones bring extreme wind conditions to possibly shut down a wind turbine.

The surface hourly mean wind speed was obtained from Taiwan Central Weather Bureau, which has set up 25 meteorological stations across Taiwan. The geographical locations and details of the 25 meteorological stations used are depicted in Fig. 2 and Table 2, respectively. Most of the meteorological stations have a 39 year data source (1961-1999) of hourly mean wind speed except five relatively new stations having 19-31 year data. As shown in Table 2, anemometer measurements at all 25 stations were taken from different heights from the ground level, which are all different from the standard height of $10 \mathrm{~m}$ above the ground level adopted by the World Meteorological Organization. To transfer the anemometer height to the standard level or other desired heights, the power law equation is herein used. 
Table 1

Wind energy characteristics for Weibull distribution and wind turbine characteristics

Wind characteristics

Mean wind speed

$$
V=c \Gamma\left(\frac{k+1}{k}\right)
$$

Standard deviation of wind speed

$$
\sigma=c \sqrt{\left[\Gamma\left(\frac{k+2}{k}\right)-\Gamma^{2}\left(\frac{k+1}{k}\right)\right]}
$$

Most probable wind speed

$$
V_{M P}=c\left(\frac{k-1}{k}\right)^{1 / k}
$$

Wind speed carrying maximum energy

$$
V_{\text {MaxE }}=c\left(\frac{k+2}{k}\right)^{1 / k}
$$

Mean wind power density

$$
\frac{P}{A}=\frac{1}{2} \rho c^{3} \Gamma\left(\frac{k+3}{k}\right)
$$

Mean wind energy density

$$
\frac{E}{A}=\frac{1}{2} \rho c^{3} \Gamma\left(\frac{k+3}{k}\right) T
$$

Wind turbine characteristics

Wind energy generated by an ideal wind turbine

Actual wind energy output from a wind turbine

Wind turbine efficiency

$$
\begin{aligned}
& E_{T W}=\frac{\rho}{2} T A \int_{V_{I}}^{V_{R}} V^{3} \frac{k}{c}\left(\frac{V}{c}\right)^{k-1} e^{-(V / c)^{k}} d V+ \\
& \frac{\rho}{2} T A V_{R}^{3} \int_{V_{R}}^{V_{O}} \frac{k}{c}\left(\frac{V}{c}\right)^{k-1} e^{-(V / c)^{k}} d V \\
& E_{T A}=T P_{R} \int_{V_{I}}^{V_{R}}\left(a_{1} V^{3}+a_{2} V^{2}+a_{3} V+\right. \\
& \left.a_{4}\right) \frac{k}{c}\left(\frac{V}{c}\right)^{k-1} e^{-(V / c)^{k}} d V+T P_{R} \int_{V_{R}} \frac{k}{c}\left(\frac{V}{c}\right)^{k-1} e^{-(V / c)^{k}} d V \\
& \eta=\frac{E_{T A}}{E_{T W}} \\
& E_{T R}=T P_{R}
\end{aligned}
$$

Rated wind energy

Capacity factor

Availability factor

$$
\begin{aligned}
& C_{F}=\frac{E_{T A}}{E_{T R}}=\int_{V_{I}}^{V_{R}}\left(a_{1} V^{3}+a_{2} V^{2}+a_{3} V+\right. \\
& \left.a_{4}\right) \frac{k}{c}\left(\frac{V}{c}\right)^{k-1} e^{-(V / c)^{k}} d V+\int_{\substack{V_{R} \\
V_{O}}}^{V_{O}} \frac{k}{c}\left(\frac{V}{c}\right)^{k-1} e^{-(V / c)^{k}} d V
\end{aligned}
$$

$$
A_{F}=P\left(V_{I} \leq V<V_{O}\right)=\int_{V_{I}} \frac{k}{c}\left(\frac{V}{c}\right)^{k-1} e^{-(V / c)^{k}} d V
$$




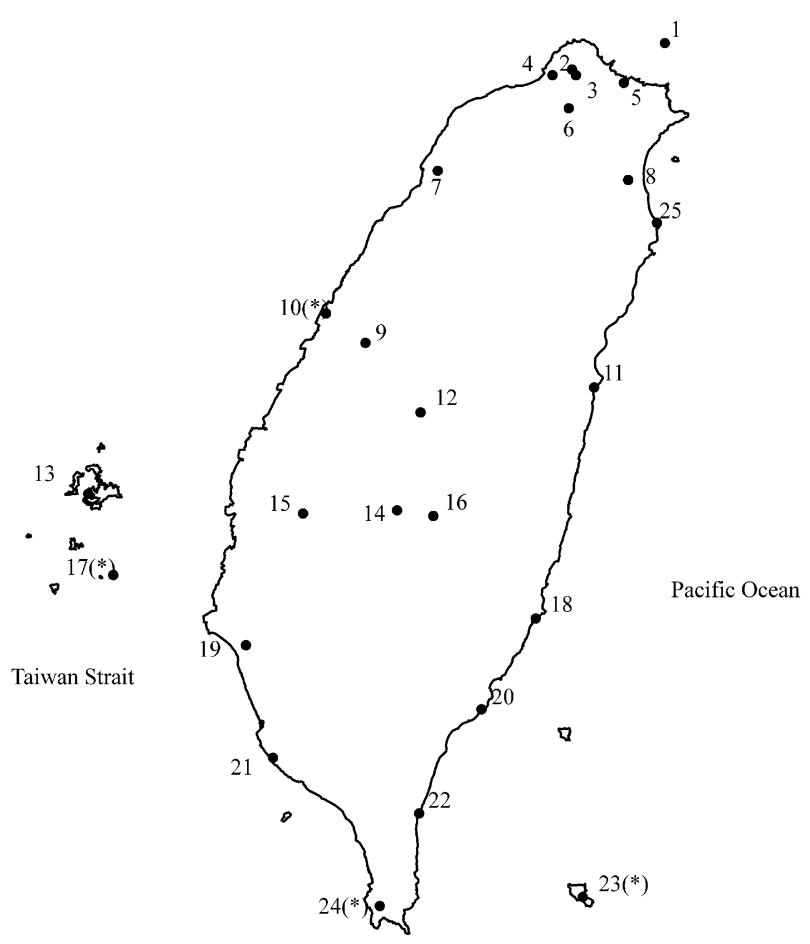

Fig. 2. Geographical locations of the meteorological stations used in the present analysis.

$$
\frac{V(z)}{V_{\delta}}=\left(\frac{Z}{\delta}\right)^{\alpha}
$$

where $V(z)$ is wind speed estimated at desired height $z, V_{\delta}$ is wind speed at boundary layer height $\delta$, and $\alpha$ is the power law index. The values of $\alpha$ and $\delta$ for each station can be also obtained in Table 2, which were estimated by Taiwan Central Weather Bureau based on local topographic conditions surrounding the stations.

From the next section, a two-stage evaluation procedure for estimating wind resource across Taiwan is carried out. The first stage is to analyze the yearly wind speed distribution as well as wind power density for the entire Taiwan. The monthly wind characteristics and wind turbine characteristics are further investigated at four high-wind meteorological stations to provide more detailed information of wind resources.

\subsection{Yearly wind characteristics of the entire Taiwan}

Based on a long-term measured data source (1961-1999) of hourly mean wind speed at 25 meteorological stations across Taiwan, the yearly wind characteristics across Taiwan, including the wind speed distribution and wind power density distribution at $10 \mathrm{~m}$ above the ground level, are obtained as shown in Figs. 3 and 4. 
Table 2

Details of the meteorological stations used in the present analysis

No. Station Years of wind Elevation Anemometer Geographical $\alpha \quad \delta$ data available from MSL height $(\mathrm{m})$ coordinates

\begin{tabular}{|c|c|c|c|c|c|c|c|}
\hline 1 & Pengchiayu & 1961-1999 & 101.7 & 12.5 & $\begin{array}{l}122^{\circ} 04^{\prime} \mathrm{E}, \\
25^{\circ} 37^{\prime} \mathrm{N}\end{array}$ & 0.110 & 233 \\
\hline 2 & Anpu & 1961-1999 & 837.6 & 7.31 & $\begin{array}{l}121^{\circ} 31^{\prime} \mathrm{E}, \\
25^{\circ} 11^{\prime} \mathrm{N}\end{array}$ & 0.110 & 233 \\
\hline 3 & Chutzehu & 1970-1999 & 607.1 & 11.03 & $\begin{array}{l}121^{\circ} 32^{\prime} \mathrm{E}, \\
25^{\circ} 09^{\prime} \mathrm{N}\end{array}$ & 0.250 & 400 \\
\hline 4 & Tanshui & 1961-1999 & 19.0 & 12.20 & $\begin{array}{l}121^{\circ} 26^{\prime} \mathrm{E} \\
25^{\circ} 09^{\prime} \mathrm{N}\end{array}$ & 0.150 & 300 \\
\hline 5 & Keelung & 1961-1999 & 26.7 & 34.60 & $\begin{array}{l}121^{\circ} 43^{\prime} \mathrm{E}, \\
25^{\circ} 08^{\prime} \mathrm{N}\end{array}$ & 0.250 & 400 \\
\hline 6 & Taipei & 1961-1999 & 5.3 & 34.90 & $\begin{array}{l}121^{\circ} 30^{\prime} \mathrm{E}, \\
25^{\circ} 02^{\prime} \mathrm{N}\end{array}$ & 0.250 & 400 \\
\hline 7 & Hsinchu & 1961-1999 & 26.9 & 15.60 & $\begin{array}{l}120^{\circ} 58^{\prime} \mathrm{E}, \\
24^{\circ} 48^{\prime} \mathrm{N}\end{array}$ & 0.194 & 350 \\
\hline 8 & Ilan & 1961-1999 & 7.2 & 26.00 & $\begin{array}{l}121^{\circ} 44^{\prime} \mathrm{E}, \\
24^{\circ} 45^{\prime} \mathrm{N}\end{array}$ & 0.150 & 300 \\
\hline 9 & Taichung & 1961-1999 & 84.0 & 17.20 & $\begin{array}{l}120^{\circ} 40^{\prime} \mathrm{E} \\
24^{\circ} 08^{\prime} \mathrm{N}\end{array}$ & 0.250 & 400 \\
\hline 10 & Wuchi & 1976-1999 & 7.2 & 33.20 & $\begin{array}{l}120^{\circ} 30^{\prime} \mathrm{E} \\
24^{\circ} 15^{\prime} \mathrm{N}\end{array}$ & 0.130 & 267 \\
\hline 11 & Hualien & 1961-1999 & 16.1 & 12.00 & $\begin{array}{l}121^{\circ} 36^{\prime} \mathrm{E}, \\
23^{\circ} 58^{\prime} \mathrm{N}\end{array}$ & 0.173 & 321 \\
\hline 12 & Sun-moon lake & 1961-1999 & 1014.8 & 8.00 & $\begin{array}{l}120^{\circ} 53^{\prime} \mathrm{E}, \\
23^{\circ} 52^{\prime} \mathrm{N}\end{array}$ & 0.150 & 300 \\
\hline 13 & Penghu & 1961-1999 & 10.7 & 14.60 & $\begin{array}{l}119^{\circ} 33^{\prime} \mathrm{E}, \\
23^{\circ} 34^{\prime} \mathrm{N}\end{array}$ & 0.150 & 300 \\
\hline 14 & A-li-shan & 1961-1999 & 2413.4 & 15.10 & $\begin{array}{l}120^{\circ} 48^{\prime} \mathrm{E}, \\
23^{\circ} 30^{\prime} \mathrm{N}\end{array}$ & 0.110 & 233 \\
\hline 15 & Chiayi & 1969-1999 & 26.9 & 14.50 & $\begin{array}{l}120^{\circ} 25^{\prime} \mathrm{E}, \\
23^{\circ} 29^{\prime} \mathrm{N}\end{array}$ & 0.167 & 313 \\
\hline 16 & Yushan & 1961-1999 & 3844.8 & 9.20 & $\begin{array}{l}120^{\circ} 57^{\prime} \mathrm{E}, \\
23^{\circ} 29^{\prime} \mathrm{N}\end{array}$ & 0.150 & 300 \\
\hline 17 & Tungchitao & 1970-1999 & 43.0 & 9.10 & $\begin{array}{l}119^{\circ} 39^{\prime} \mathrm{E}, \\
23^{\circ} 15^{\prime} \mathrm{N}\end{array}$ & 0.125 & 260 \\
\hline 18 & Chengkung & 1961-1999 & 33.5 & 12.80 & $\begin{array}{l}121^{\circ} 21^{\prime} \mathrm{E}, \\
23^{\circ} 05^{\prime} \mathrm{N}\end{array}$ & 0.144 & 245 \\
\hline 19 & Tainan & 1961-1999 & 8.1 & 37.60 & $\begin{array}{l}120^{\circ} 11^{\prime} \mathrm{E} \\
22^{\circ} 59^{\prime} \mathrm{N}\end{array}$ & 0.218 & 378 \\
\hline 20 & Taitung & 1961-1999 & 9.0 & 11.40 & $\begin{array}{l}121^{\circ} 08^{\prime} \mathrm{E}, \\
22^{\circ} 45^{\prime} \mathrm{N}\end{array}$ & 0.150 & 300 \\
\hline 21 & Kaohsiang & 1961-1999 & 2.3 & 14.00 & $\begin{array}{l}120^{\circ} 18^{\prime} \mathrm{E} \\
22^{\circ} 34^{\prime} \mathrm{N}\end{array}$ & 0.105 & 300 \\
\hline 22 & Tawu & 1961-1999 & 8.1 & 12.70 & $\begin{array}{l}120^{\circ} 53^{\prime} \mathrm{E}, \\
22^{\circ} 21^{\prime} \mathrm{N}\end{array}$ & 0.244 & 407 \\
\hline 23 & Lanyu & 1961-1999 & 324.0 & 12.50 & $\begin{array}{l}121^{\circ} 33^{\prime} \mathrm{E} \\
22^{\circ} 02^{\prime} \mathrm{N}\end{array}$ & 0.110 & 233 \\
\hline 24 & Hengchun & 1961-1999 & 21.9 & 14.30 & $\begin{array}{l}120^{\circ} 44^{\prime} \mathrm{E} \\
22^{\circ} 00^{\prime} \mathrm{N}\end{array}$ & 0.194 & 350 \\
\hline 25 & Suao & 1981-1999 & 24.9 & 34.00 & $\begin{array}{l}121^{\circ} 51^{\prime} \mathrm{E}, \\
24^{\circ} 36^{\prime} \mathrm{N}\end{array}$ & 0.150 & 300 \\
\hline
\end{tabular}




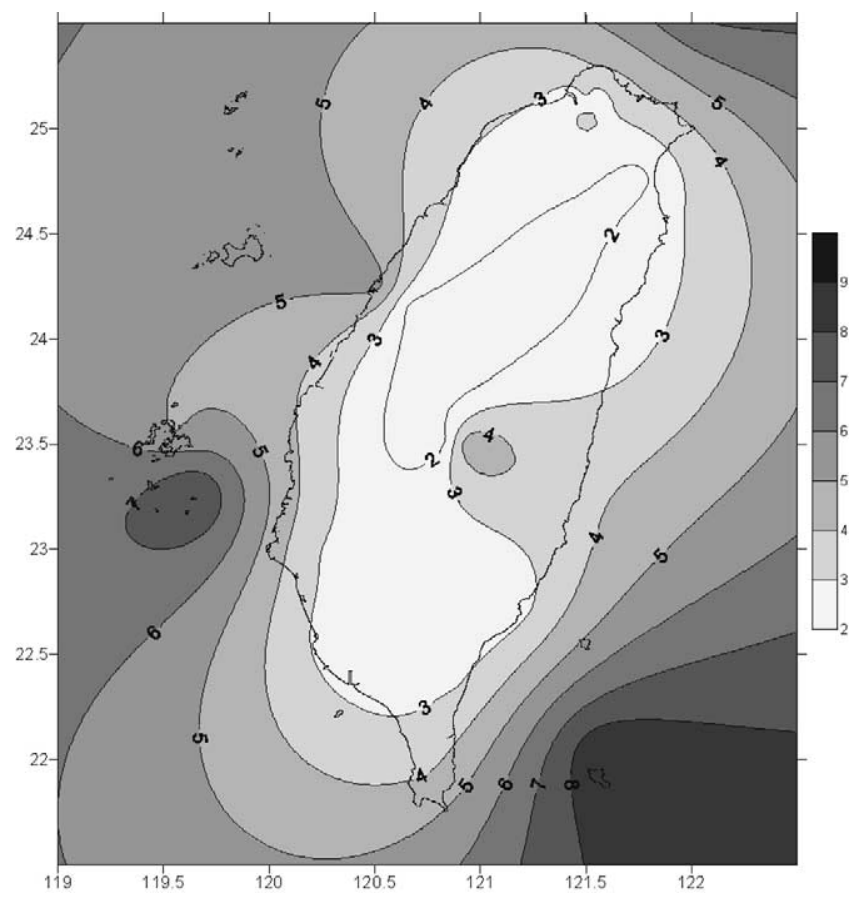

Fig. 3. Yearly wind speed distribution of Taiwan (10 m over the ground level, $\mathrm{m} / \mathrm{s})$.

These two figures show all the favorable features of the spatial distribution of wind energy potential in Taiwan. According to the results, Taiwan has a significant wind resource in the areas along the western coastline, southern peninsula, and several small surrounding islands. These areas generally have good mean wind speeds and wind energy potential, which are greater than $4 \mathrm{~m} / \mathrm{s}$ and $200 \mathrm{~W} / \mathrm{m}^{2}$. On the contrary, the inland parts and the eastern coast bands have less wind energy potential of about two-times lower.

\subsection{Monthly wind characteristics}

As introduced earlier, the patterns of the yearly and monthly mean wind speed across Taiwan have significant spatial and temporal variations due to the combined effect of various mechanisms. The yearly wind characteristics of Taiwan as shown in Figs. 3 and 4 can only give annually spatial mean information, which is merely a partial picture of wind energy potential. To overcome this drawback, four highwind meteorological stations (the $*$ signs in Fig. 2) have been selected to further study the monthly wind characteristics and monthly wind turbine characteristics. Wuchi (No. 10) is situated in the narrow strip of the western coastline. Hengchun (No. 24) is located at the end of the southern peninsula. Tungchitao (No. 17) and Lanyu (No. 23) are the small surrounding islands in Taiwan Strait and Pacific Ocean, 


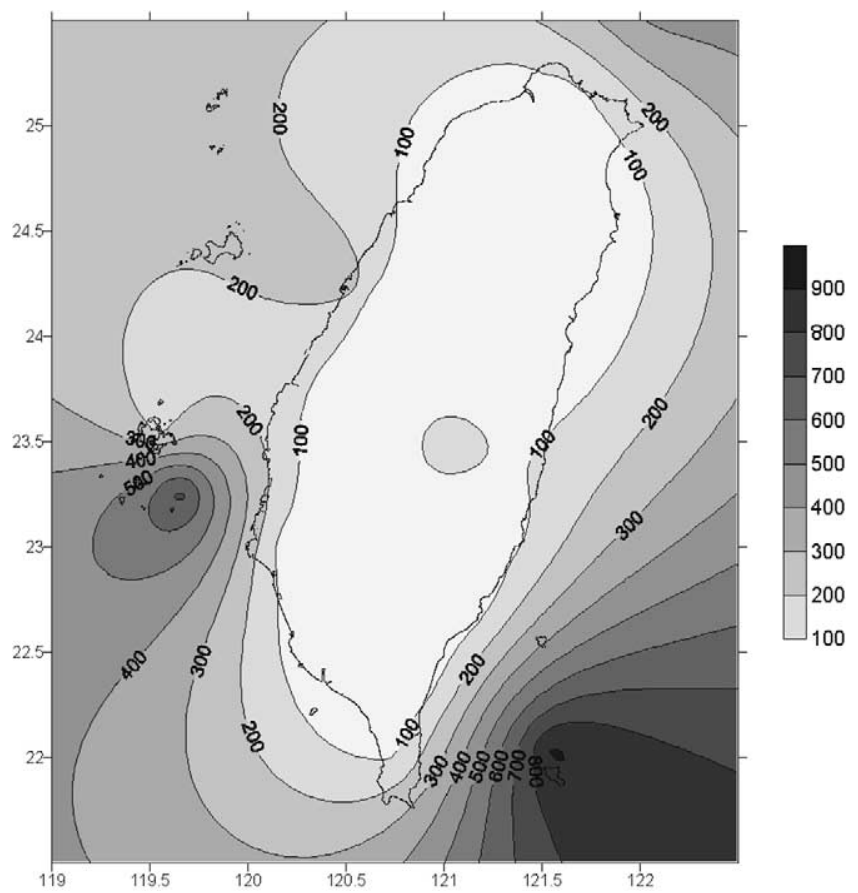

Fig. 4. Yearly wind power density distribution of Taiwan $\left(10 \mathrm{~m}\right.$ over the ground level, $\left.\mathrm{W} / \mathrm{m}^{2}\right)$.

respectively. The Vestas V47-660 KW turbine (Fig. 1) with a hub height of $45 \mathrm{~m}$ is selected as the study turbine.

Using the expressions described in Table 2, the monthly wind characteristics of the four high-wind stations are summarized in Figs. 5 and 6 and Tables 3-6. For easy comparison, 30 days are taken for each month. It is clear from these results that these four high-wind locations, situated in different regions of Taiwan, are generally characterized by high mean wind speeds with seasonal regularity. During the period

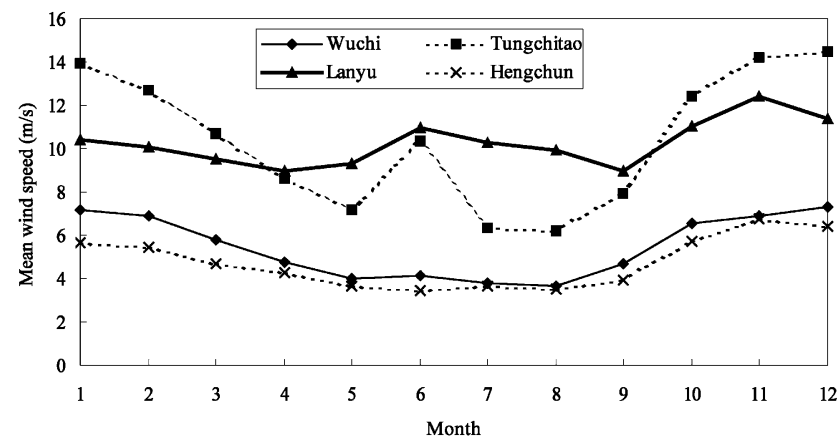

Fig. 5. Monthly mean wind speed for the four high-wind stations studied. 


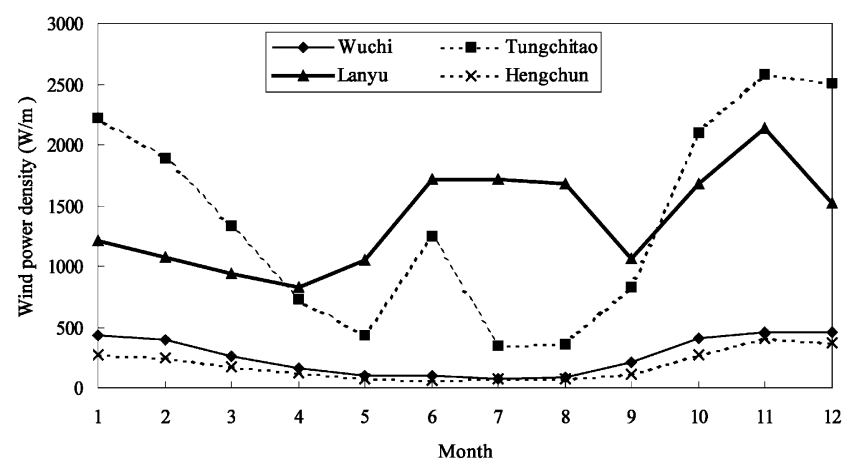

Fig. 6. Monthly mean wind power density for the four high-wind stations studied.

between October and March, owing mainly to the trade winds these regions are associated with strong winds, showing high wind energy potential. In contrast, from April to September (the Asia monsoon season) these regions exhibit relative low wind regimes. Among the four stations studied, Tungchitao and Lanyu possess outstanding wind energy potential compared to the other two stations. Lanyu tends to experience strong and steady winds. The highest mean wind speed $12.41 \mathrm{~m} / \mathrm{s}$ with the mean wind power density up to $2136 \mathrm{~W} / \mathrm{m}^{2}$ is in November, while the lowest is $8.98 \mathrm{~m} / \mathrm{s}$ together with $821 \mathrm{~W} / \mathrm{m}^{2}$ in April, demonstrating less wind speed fluctuation and more reliable wind energy potential.

\subsection{Monthly wind turbine characteristics}

In addition to the monthly wind characteristics, the monthly wind turbine characteristics in Table 2 are also analyzed. Three fundamental types of monthly wind turbine characteristics, the availability factor, the capacity factor, and the wind turbine efficiency of the wind turbine used, are emphasized as shown in Figs. 7-9 and Tables 3-6. Fig. 7 shows that these four high-wind locations have the similar tendency of seasonal variation on the availability factor. The availability factor is in the range from 0.658 (August) to 0.986 (December) for Tungchitao, showing good operation percentage. For Hengchun, the highest is 0.717 in November, while the lowest 0.346 occurs in June, indicating that the cut-in speed of the wind turbine used is too high in this region.

It can be seen from Fig. 8 that Tungchitao and Lanyu, possessing outstanding wind speed and wind power density, as shown in Figs. 5 and 6, still have high capacity factors. The highest and lowest capacity factor is 0.818 in December and 0.266 in August for Tungchitao, and 0.642 in November and 0.450 in September for Lanyu. Fig. 8 also demonstrates that Lanyu has less variation of the capacity factor for the entire year, which is similar to wind power density. The monthly wind turbine efficiency for the four high-wind stations studied has been plotted in Fig. 9. In this figure, an opposite trend can be observed. The regions with high wind speeds like Tungchitao and Lanyu have less wind turbine efficiency than the low wind 


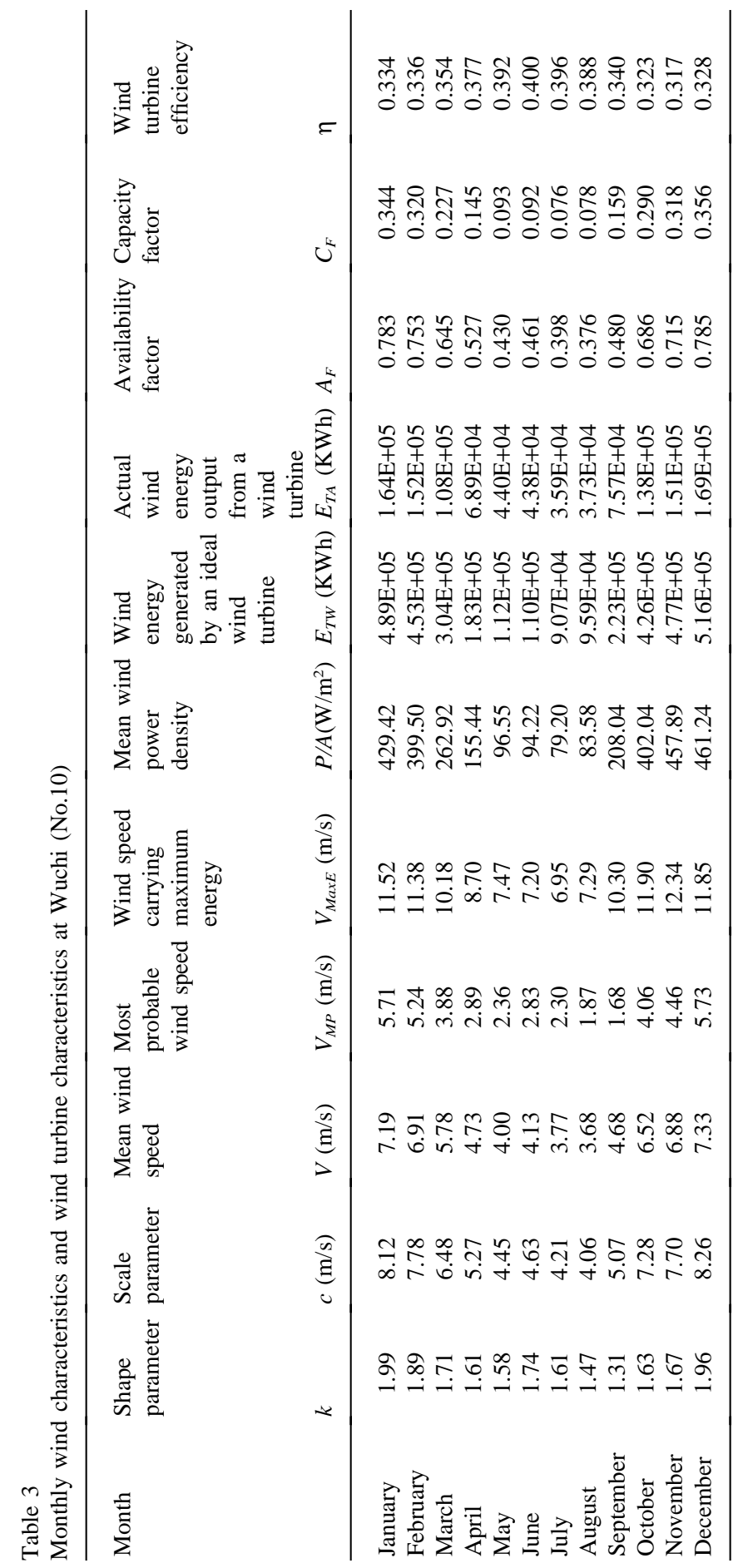




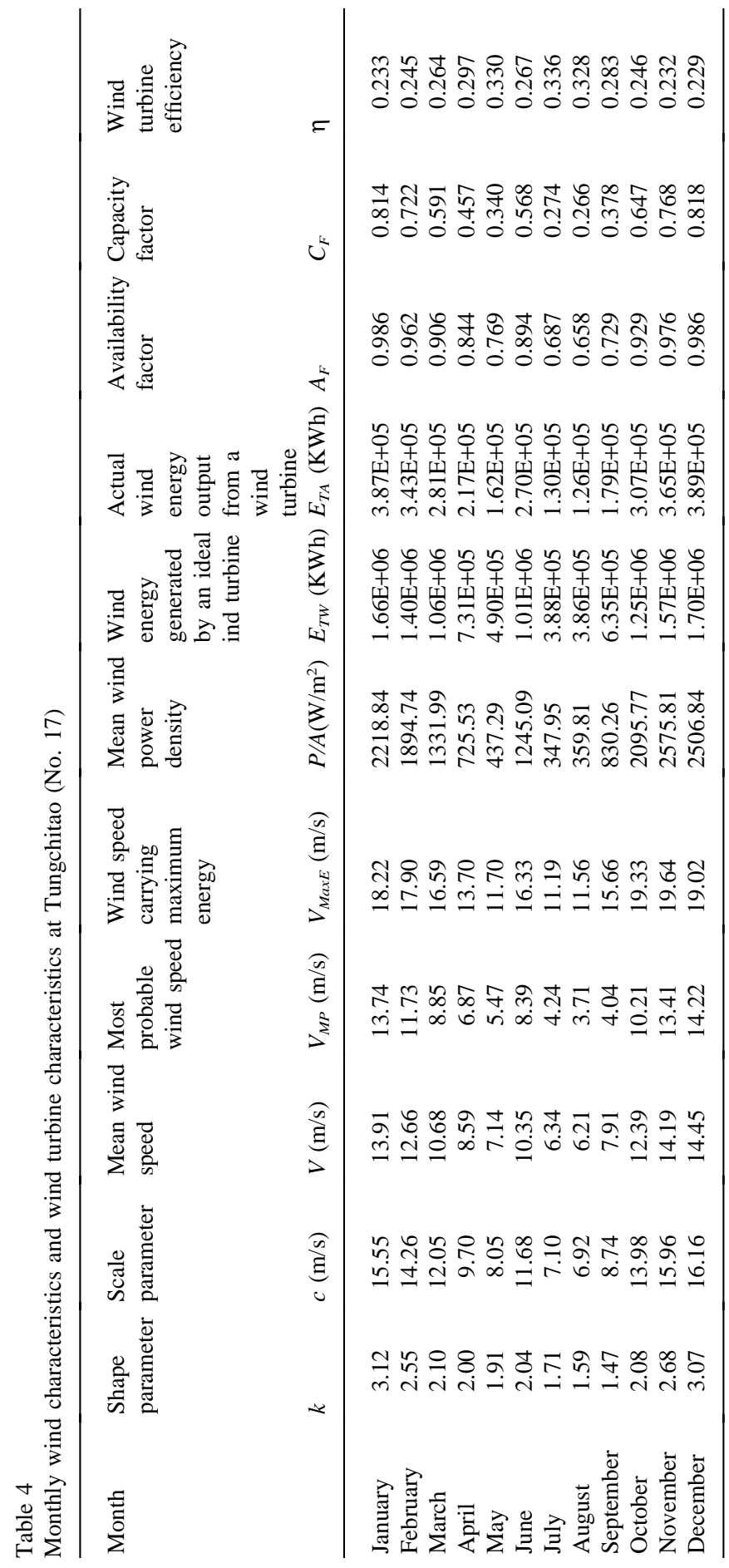




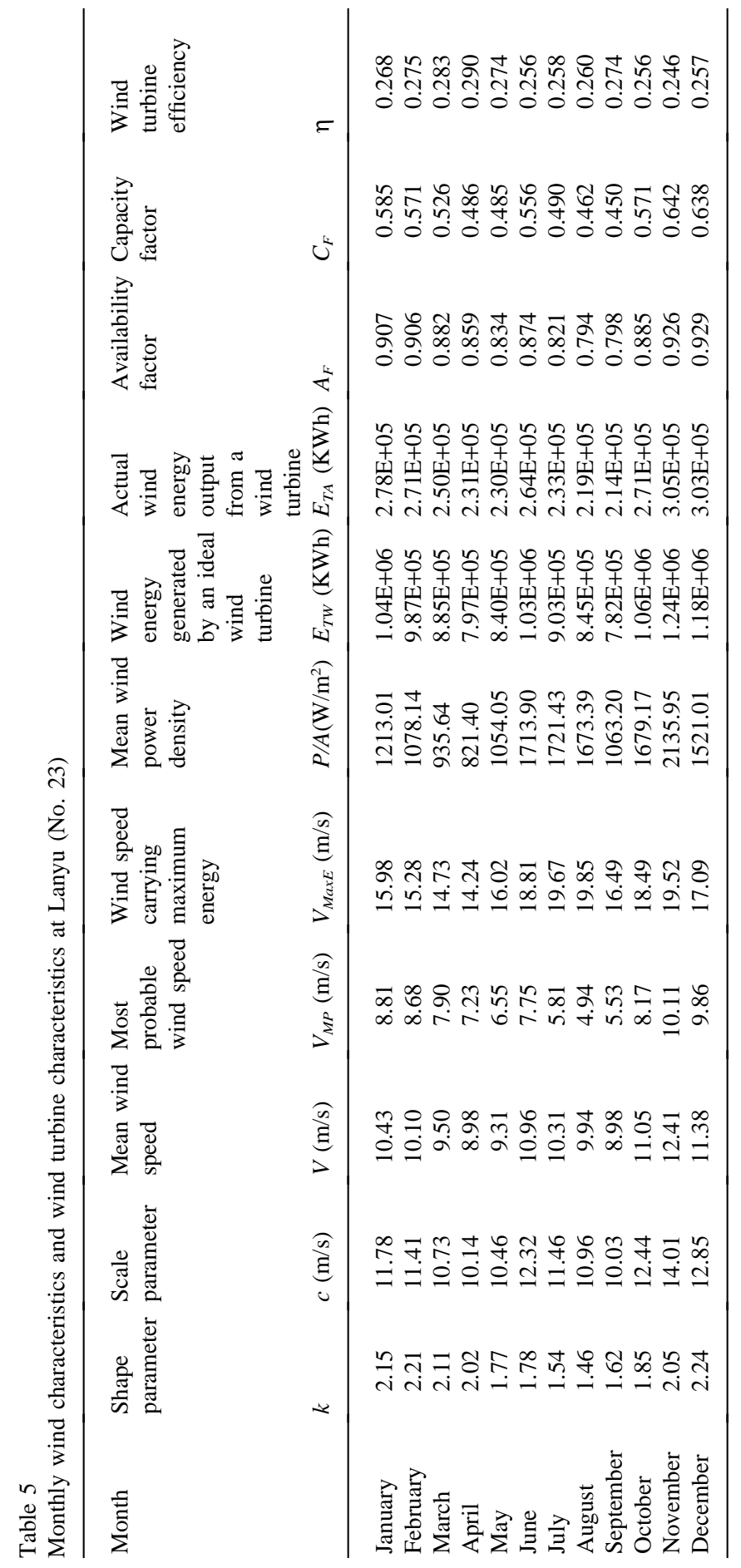




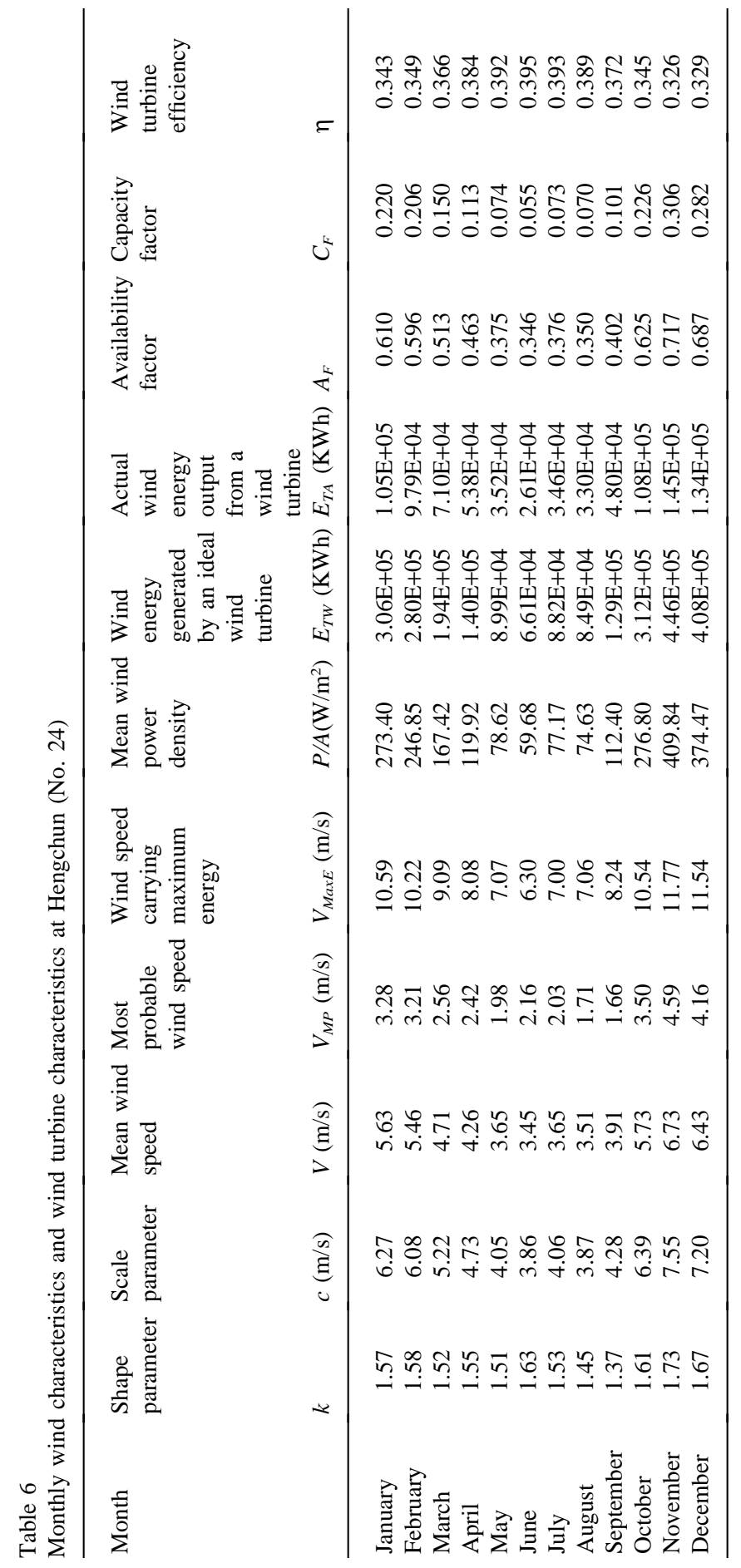




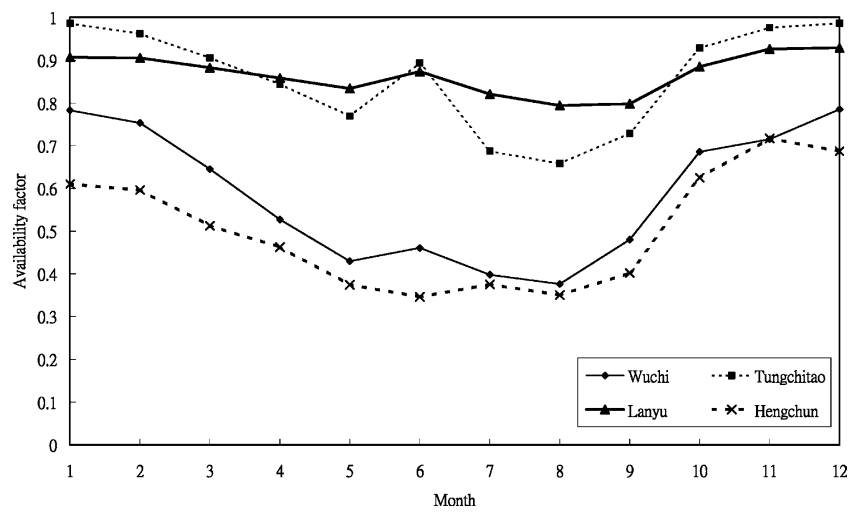

Fig. 7. Monthly availability factor for the four high-wind stations studied.

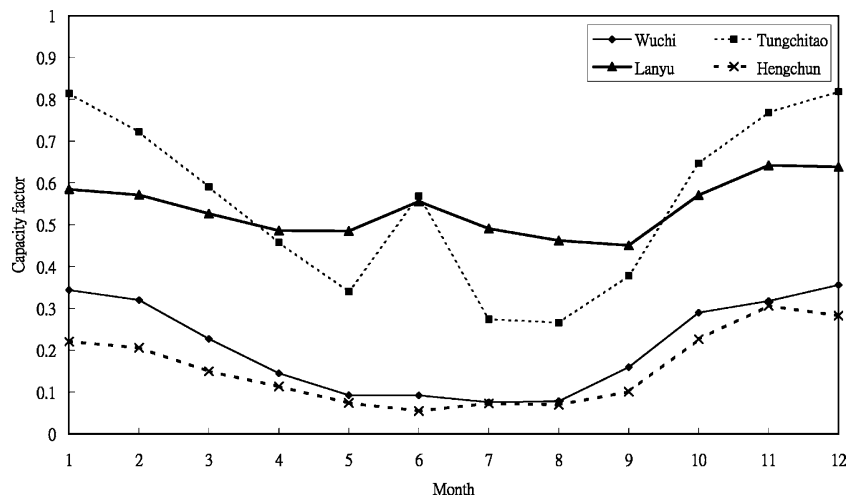

Fig. 8. Monthly capacity factor for the four high-wind stations studied.

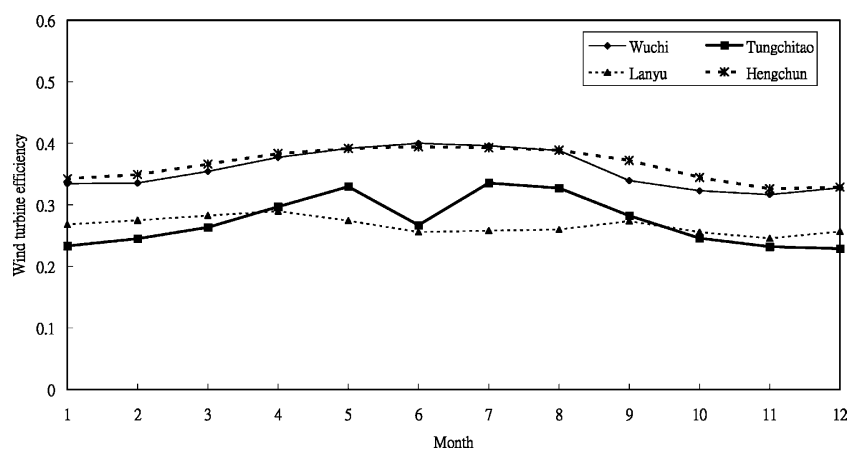

Fig. 9. Monthly wind turbine efficiency for the four high-wind stations studied. 
regions like Wuchi and Hengchun. This is because the V47-660 KW turbine is operating a constant rated power at wind speeds between the rated and cut-off wind speed. Meanwhile, the energy available in the wind is still proportional to the cubic of wind speed. The wind turbine efficiency is thus decreasing as the wind speed probability distributed between the rated speed and cut-off speed is increasing. As a result, using the V47-660 KW turbine in the high wind regions like Tungchitao and Lanyu is equivalent to using a large rotor with a very small generator. The wind turbine used would run at full capacity with a high capacity factor, but it could produce very little electricity, resulting in low wind turbine efficiency. This information implies that a wind turbine with more output rated power is more adequate for the regions like Tungchitao and Lanyu, by which the capacity factor is reduced but the wind turbine efficiency is raised.

\section{Conclusions}

A two-stage evaluation procedure has been carried out to investigate wind characteristics and wind turbine characteristics in Taiwan by means of a 39 year data source (1961-1999) of hourly mean wind speed and a newly developed mathematical formulation. The yearly wind speed distribution and wind power density across Taiwan is firstly evaluated to provide basic information of wind resource, which indicates that there exists outstanding wind resource in the areas along the western coastline, southern peninsula, and several small surrounding islands. The monthly wind speed distributions, the monthly wind power densities, the wind energy generated by an ideal turbine, and the actual wind energy generated by a wind turbine, are further estimated as shown in Tables 3-6. Three fundamental types of monthly wind turbine characteristics (the availability factor, the capacity factor, and the wind turbine efficiency of the wind turbine used) for different high-wind locations are calculated and integratedly assessed to map out wind energy resource in Taiwan. For Lanyu station (No. 23), the availability factor for the entire year varies from 0.794 to 0.929 , the wind turbine efficiency for the entire year is located between 0.246 and 0.290 , and the capacity factor is in the range between 0.450 and 0.642 . The results show the general availability of wind characteristics and wind turbine characteristics across Taiwan.

\section{Acknowledgements}

The authors would like to acknowledge the financial support for this work provided by Council of Research and Development, National Taiwan University.

\section{References}

[1] ECROC (Energy Commission of the Republic of China), White paper of energy policy of the Republic of China. Taipei, Taiwan, 2000. 
[2] Ackermann T, Söder L. An overview of wind energy-status 2002. Renewable and Sustainable Energy Reviews 2002;6:67-128.

[3] Patel MR. Wind and solar power systems. Florida, America: CRC Press, 1999.

[4] Jamil M, Parsa S, Majidi M. Wind power statistics and an evaluation of wind energy density. Renewable Energy 1995;6(5):623-8.

[5] Rosen KR, Van Buskirk R, Garbesi K. Wind energy potential of coastal Eritrea: an analysis of sparse wind data. Solar Energy 1999;66(3):201-13.

[6] Li G. Feasibility of large scale offshore wind power for Hong Kong - a preliminary study. Renewable Energy 2000;21:387-402.

[7] Lu L, Yang H, Burnett J. Investigation on wind power potential on Hong Kong-an analysis of wind power and wind turbine characteristics. Renewable Energy 2002;27:1-12.

[8] Mathew S, Pandey KP, Kumar A. Analysis of wind regimes for energy estimation. Renewable Energy 2002;25:81-99.

[9] Jangamshetti SH, Rau VG. Site matching of wind turbine generators: a case study. IEEE Transactions on Energy Conversion 1999;14(4):1537-43.

[10] Balouktsis A, Chassapis D, Karapantsios TD. A nomogram method for estimating the energy produced by wind turbine generators. Solar Energy 2002;72(3):251-9.

[11] Stevens MJM, Smulders PT. The estimation of parameters of the Weibull wind speed distribution for wind energy utilization purposes. Wind Engineering 1979;3(2):132-45.

[12] Vestas-American Wind Technology, Inc. Manufacturer's brochure, 2002. 